\title{
ESPORTE, VIOLÊNCIA E CIVILLZACÃO: UMA ENTREVISTA COM ERIC DUNNING
}

\section{Édison Gastaldo}

Universidade do Vale do Rio dos Sinos - Brasil

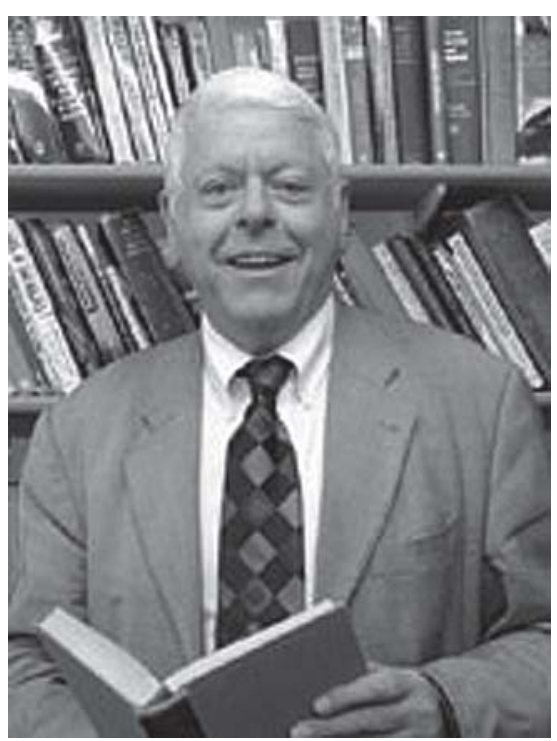

Eric Dunning.

Eric Dunning é hoje um dos mais célebres cientistas sociais britânicos, e uma referência mundial no âmbito da sociologia dos esportes. Aluno e colaborador próximo de Norbert Elias desde os anos 1950, ele ocupa hoje a posição honorífica de Professor Emérito no Departamento de Sociologia da Universidade de Leicester, no norte da Inglaterra. Membro destacado da chamada "Escola de Leicester” na sociologia, o professor Dunning publicou diversos livros fundamentais para a abordagem do fenômeno esportivo pelas ciências sociais, a maior parte deles, infelizmente, ainda não traduzida para o português. Destaca-se entre eles o clássico A Busca da Excitação (The Quest for Excitement), escrito em parceria com Norbert Elias em 1986, e publicado em português pela Difel, de Portugal. Neste livro, o surgimento das diferentes modalidades esportivas no Ocidente (na Inglaterra, mais especificamente) é investigado a partir da perspectiva eliasiana do processo civilizatório. Outro tema que celebrizou internacionalmente o professor Dunning foi o hooliganismo. Pioneiro na investigação deste tema, publicou livros como Sport Matters (1999) e Fighting Fans: Football Violence as a World Problem (2002). No final de 2007, o professor Dunning foi homenageado em uma coletânea de artigos publicada 
pela editora inglesa Routledge, intitulada Matters of Sport: Essays in Honour of Eric Dunning.

Nesta entrevista, Eric Dunning fala da sua relação com Elias e os bastidores da produção de seu clássico, sobre hooliganismo, esporte e globalização, bem como das atividades de seu grupo de pesquisadores do esporte contemporâneo.

Uma nota com relação à tradução: na entrevista, o professor Dunning faz referência a diversos esportes diferentes, que na origem se chamavam football, como o rugby, o futebol americano e o football association, nome completo do esporte que no Brasil denominamos "futebol”. Sempre que esta distinção se fez necessária, mantive o qualificativo em inglês, "futebol association".

Édison Gastaldo: Em 1986, o senhor e Norbert Elias publicaram um dos livros mais influentes de toda a Sociologia do Esporte, The Quest for Excitement - em português, A Busca da Excitação (Elias; Dunning, 1995). Como o senhor avalia a relevância desta obra passados mais de vinte anos de sua publicação? Como o senhor conheceu Norbert Elias e como foi trabalhar com ele?

Eric Dunning: Conheci Elias em 1956, quando entrei para o que era então a University College Leicester, como estudante de graduação em Economia. Eu nunca tinha ouvido falar em Sociologia até então, mas meu encontro com Elias fez-me desejar ser um sociólogo acadêmico muito mais do que um economista. Eu jogava nas equipes de cricket e futebol da Universidade, e, quando eu me graduei em 1959, Elias sugeriu que seria uma boa idéia ficar e fazer um mestrado sobre esportes. Segui o conselho, e em dois anos Elias e eu começamos a escrever juntos sobre o que era então uma nova especialidade sociológica, a Sociologia do Esporte. Um dia reunimos os ensaios que havíamos escrito juntos e outros que escrevemos separadamente para fazer o livro The Quest for Excitement. Uma edição nova e revisada deste livro deve ser publicada em 2008 pela University College Dublin Press. Traduções dele já foram publicadas em francês, alemão, italiano, espanhol, português, grego, holandês, japonês e húngaro. A relevância deste livro, na minha opinião, é duradoura porque ele demonstra claramente que os esportes modernos emergem em primeiro lugar como parte de um "processo civilizatório” e que a principal função do esporte é a produção de excitação prazerosa e socialmente construtiva, e que ele serve também para criar oportunidades de sociabilidade e movimento em uma variedade de formas complexas e controladas, como dança e ginástica, por exemplo, além de permitir formar identidades e pô-las à prova. 
A edição de 2008 do livro também inclui um capítulo novo e atualizado sobre hooliganismo, um ensaio de Elias inédito até hoje, e é completamente comentado de modo a mostrar a contínua relevância e valor desta obra, e para acrescentar e atualizar os argumentos quando necessário.

Édison Gastaldo: O hooliganismo sempre foi um dos principais temas investigados pela Sociologia do Esporte, e o senhor é internacionalmente reconhecido como uma autoridade neste tópico. À primeira vista, os hooligans parecem desafiar a idéia de um papel "civilizatório" atribuído aos esportes nas sociedades ocidentais. Mesmo com severo controle policial sobre o hooliganismo, parece que episódios de violência e intolerância são sempre possíveis, e assim se tornaram parte constitutiva do universo do futebol. Por outro lado, cenas de conduta violenta entre torcedores são evidentemente mais “espetaculares” para a mídia do que uma conduta ordeira e cotidiana, e isso pode levar a uma definição "exagerada” da situação por parte da mídia. Como o senhor vê o hooliganismo? Trata-se de um mero caso de delinqüência ou o sintoma de uma crise mais ampla nas sociedades ocidentais?

Eric Dunning: Na Inglaterra, o hooliganismo emergiu inicialmente como um fenômeno definido como um sério “problema social” pela mídia, pelas autoridades futebolísticas e pelo governo nos anos 1960. Formas de hooliganismo já haviam ocorrido em outras partes do mundo, por exemplo, na Escócia, Irlanda do Norte e países "latinos" da Europa e América do Sul, mas neste período, grosso modo, entre os anos 1930 e 1950, acreditava-se que a Inglaterra era o lar do fair play e do "espírito esportivo," e que nossos torcedores eram universalmente pacíficos e bem-comportados.

O hooliganismo não se tornou um tema fundamental para a sociologia do esporte até os anos 1970, mesmo que, de fato, a violência entre torcedores vinculados ao futebol tenha uma história na Grã Bretanha - até mesmo na Inglaterra! - que se estende até os primeiros dias do jogo moderno, entre os anos 1870 e 1880 . O termo "hooligan” em si data dos anos 1890 - supostamente, seria uma corruptela de "Houlihan," o nome de uma violenta família irlandesa que vivia em Londres - e o termo "hooligan” aplicado ao futebol parece ter sido usado pela primeira vez com relação a derbies ${ }^{1}$ nos anos 1920.

\footnotetext{
1 Jogos entre times rivais de uma mesma localidade, como no Brasil o Fla-Flu e o Gre-Nal. (N. de T.).
} 
O que se segue do que eu disse até aqui é que, na Inglaterra, distúrbios de massa relacionados ao futebol eram vistos até os anos 1960 como um problema das autoridades futebolísticas, e não como um problema dos governos locais ou nacionais ou mesmo da polícia. Na verdade, a pesquisa histórica revelou que a incidência registrada de violência ligada ao futebol era alta na Grã-Bretanha nos anos anteriores à Primeira Guerra Mundial, diminuiu no período entre-guerras na Inglaterra, embora não tenha chegado a zero, período em que não se alterou na Escócia nem na Irlanda do Norte (nos dois casos, as taxas foram sustentadas pelo alto nível de tensão entre católicos e protestantes), permaneceram baixas até os anos 1950, e então começaram a crescer substancialmente em conjunção com um "pânico moral” promovido pela mídia e pelo temor associado à possibilidade de que, ao sediar a Copa do Mundo de 1966, a reputação mundial da Inglaterra como o lar do fair-play e do "espírito esportivo" ficasse seriamente comprometida. Havia um problema crescente naquela época associado à delinqüência juvenil, como os teddy boys, os mods, os rockers e os skinheads, mas o pânico da mídia contribuiu para a produção de uma "profecia autocumprida”, no curso da qual o problema do hooliganismo se tornou realmente pior. Os estádios de futebol passaram a ser definidos por candidatos a hooligan como arenas, para onde sempre iam "forasteiros" prontos para ser atacados. A mídia explorou este fato. Depois de 1966, os "skinheads", com suas cabeças raspadas e sua forma de vestir típica da classe trabalhadora se tornaram a forma arquetípica do hooligan, mesmo que alguns deles tivessem vindo (e ainda vêm) de ambientes "respeitáveis” de classe média.

Assim, na Grã-Bretanha, o hooliganismo no futebol não é nenhuma novidade. Suas manifestações ocorrem desde 1870, mas houve um período entre 1930 até meados dos anos 1950 em que os ingleses viam o hooliganismo como um problema para o resto do mundo, mas não para eles mesmos. Houve um esquecimento coletivo sobre os problemas com o futebol nos anos 1920 e antes da Primeira Guerra Mundial. Na verdade, no contexto desta "amnésia coletiva”, eles também se esqueceram das violentas formas de futebol popular das quais o jogo moderno, mais “civilizado", descende, e que podem ser vistas como antecedentes não somente do jogo moderno, mas também do próprio hooliganismo. Tentativas mal-sucedidas das autoridades para abolir estas formas populares de jogo e conter sua violência destrutiva podem ser seguramente localizadas pelo menos desde o século XIV!

As formas modernas de futebol - futebol association, rugby, etc. - surgiram no século XIX como parte do que Norbert Elias chamou de "processo 
civilizatório”. Do modo como Elias os compreendeu, processos civilizatórios não são simples, lineares e “progressivos”, mas formações complexas, que são como ondas, com múltiplos níveis e que ocorrem no nível dos indivíduos tanto quanto no das sociedades. Ele também escreveu sobre "processos decivilizatórios”, que podem ocorrer de modo mais ou menos rápido, em maior ou menor escala, por exemplo, a "falência da civilização" que ocorreu na Alemanha, sua terra natal, e que permitiu aos nazistas chegar ao poder. É necessário e relevante discutir tudo isso no contexto presente, porque há um crescente volume de evidências que sugerem que, desde os anos 1960, sociedades de todo o Ocidente têm enfrentado processos de-civilizatórios substanciais ao longo dos quais a violência aumentou. A onda mundial de hooliganismo no futebol contemporâneo pode ser vista como parte desta tendência mundial.

É preciso ainda discutir o suposto papel “civilizador” dos esportes. Esta idéia surgiu no século XIX e depende, para sua operacionalização, da inculcação nos jovens, desde muito cedo, dos valores do amadorismo, como o fair play e a idéia de que competir é mais importante do que vencer. O profissionalismo mistura do esporte com valores orientados pelo dinheiro -, a atitude de "vencer-a-qualquer-custo" que acompanha o esporte profissional e a pressão derivada do número de equipes e número de espectadores fazem com que seja difícil a sobrevivência de atitudes e valores amadores como o fair play. Costumava-se referir os esportes modernos como formas de "guerra sem armas". Na minha opinião, a despeito de todos os problemas gerados pelos esportes, eles são muito, muito melhores do que a guerra, especialmente dado o poder de destruição das armas modernas. Os esportes são locais para a geração de excitação prazerosa, amizade e sociabilidade. Eles são uma grande invenção coletiva, que consegue com sucesso resolver a aparente contradição entre rivalidade e amizade. Pode-se dizer que os esportes são formas de "rivalidade amistosa”, e como tais, são extremamente valiosos.

Édison Gastaldo: A internacionalização do futebol se aprofundou em anos recentes, embora não seja exatamente uma novidade. Este processo trouxe temas muito complexos para a antropologia dos esportes, como a migração de atletas cada vez mais jovens da América Latina e África para a Europa e a Ásia, uma inflação geral no valor das transferências e dos salários, juntamente com freqüentes episódios envolvendo racismo e identidades nacionais. Como o senhor avalia este processo e suas implicações? 
Eric Dunning: A internacionalização do futebol é um processo de longo termo, que pode ser encontrado desde o final do século XIX. Assim como os Jogos Olímpicos modernos - em oposição aos da Antigüidade - que também datam do mesmo período, a mentalidade organizacional e política francesa colaborou na difusão mundial do futebol association, que era originalmente uma invenção sócio-cultural britânica, impregnado de valores como o fair play. Este processo geral tomou parte na grande tendência rumo ao que hoje chamamos "globalização".

O esporte foi tão bem sucedido em atrair pessoas na condição de jogadores, torcedores, árbitros e administradores, que valores profissionais e financeiros vieram a tomar crescentemente a cena, marginalizando e em alguns casos eliminando os valores associados com o fair play.

A tendência de comercialização e profissionalização global do futebol tem sido exacerbada no contexto da mídia, particularmente da televisão, um processo que contribuiu para tornar os valores econômicos mais importantes do que os valores esportivos. Ela levou, por exemplo, à anomia crônica de alguns dos jogadores mais bem-pagos, George Best e Paul Gascoigne são alguns exemplos ingleses. Ambos, incapazes de lidar com a súbita fama e riqueza, tornaram-se alcoólicos crônicos. O que pode ser chamado de hipercomercialização contribuiu para que as principais ligas européias tivessem o capital financeiro para importar e explorar o trabalho futebolístico de suas antigas colônias na África e América do Sul, e a problemas com conflitos internacionais e derivados das assim chamadas diferenças "raciais”. Formas de hooliganismo ligadas ao futebol surgiram em escala global (ver Dunning et al., 2002).

Tristemente, a maioria dos jogadores e torcedores de futebol, do hemisfério sul ou do norte, do oriente ou do ocidente, parecem estar mais interessados na vitória de seus times do que em trabalhar coletivamente para combater estes males variados e complexos. Entretanto, campanhas organizadas, baseadas em conhecimento, são necessárias caso o futebol - e o esporte em geral resolva cumprir sua promessa de integração social de pessoas diferentes em cada vez mais larga escala, e de dar às pessoas sentido e emoção em um mundo cada vez mais secular, e no qual o conflito e a tensão podem aumentar consideravelmente, como conseqüência do aquecimento global e outros problemas contemporâneos que, pela primeira vez na história humana, são de caráter evidentemente global, e terão que ser enfrentados neste nível, e não simplesmente de modo local em cada Estado-Nação. 
Édison Gastaldo: O senhor foi um dos fundadores do Sir Norman Chester Centre For Football Research, atualmente o "Centro de Sociologia do Esporte" da Universidade de Leicester, uma iniciativa pioneira na Europa, e talvez no mundo. Como foi o processo de institucionalização da sociologia do esporte na Inglaterra? A que atividades o Centro se dedica neste momento?

Eric Dunning: A sociologia do esporte começou a emergir como uma especialidade sociológica nos anos 1960. Este processo foi marcado pela formação, naquela década, do International Committee for Sport Sociology (ICSS), atualmente chamada International Sociology of Sport Association (ISSA), uma organização que foi e permanece sendo verdadeiramente internacional, embora conte com relativamente poucos membros de países do Terceiro Mundo, especialmente em seus primórdios.

A principal personalidade na formação do ICSS foi o sociólogo alemão Guenther Lueschen. Ele foi auxiliado por colegas como o educador físico inglês Peter McIntosh, o sociólogo americano Gregory Stone, o educador físico polonês Andrzej Wohl e, é claro, por Norbert Elias e por mim. O ICSS foi uma organização literalmente internacional e refletiu o fato de que os anos 1960 testemunharam o crescimento das tensões da assim chamada "Guerra Fria" entre oriente e ocidente, tensões que se manifestaram sobretudo na "Crise dos Mísseis" em Cuba, em 1962, uma crise que chegou perto da troca de disparos de mísseis que transportavam bombas de hidrogênio entre a URSS e os EUA. Em um contexto como esse, o ICSS parecia ser uma instituição de grande valor potencial, por conta do uso hipotético do esporte no desarme das tensões internacionais e porque, para insistir em um ponto do qual falei anteriormente, esta organização era um dos poucos contextos naqueles anos em que pessoas de todo o mundo podiam se encontrar amistosamente e em termos formalmente igualitários.

Fui encorajado por Norbert Elias, entre 1959 e 1962, a escrever uma dissertação de mestrado sobre futebol, e, portanto, estávamos em condições de contribuir naqueles estágios iniciais do desenvolvimento da sociologia do esporte. Estávamos entre os conferencistas magistrais do primeiro congresso internacional do ICSS, por exemplo. Este congresso tratou de pesquisas sobre esportes em pequenos grupos e ocorreu em Colônia, na Alemanha, em 1966.

O paper que apresentamos se chamava "Dinâmicas de grupos esportivos com referência especial ao futebol”. Um ponto central em nosso argumento foi o fato de que as evidências que eu coletara no desenvolvimento da história 
inicial do futebol apoiava fortemente a idéia de que o processo geral seria melhor interpretado como tendo ocorrido como parte do que Elias chamava de “processo civilizatório”. Entretanto, o surgimento do hooliganismo futebolístico na Grã-Bretanha e sua subseqüente dispersão pelo mundo levou à crítica de que, se não fosse um processo no sentido oposto, um processo "de-civilizatório" estava em curso. Isto levou a mim e a meu colega Patrick Murphy a buscar recursos junto ao que então se chamava Social Sciences Research Council. Fomos bem sucedidos em nossa demanda, e contratamos um estudante de pósgraduação, John Williams, como nosso assistente de pesquisa. Dois livros importantes resultaram de nosso trabalho: The Roots of Football Hooliganism: an Historical and Sociological Study (Dunning; Murphy; Williams, 1988) e Football on Trial: Spectator Violence and Development in the Football World (Murphy; Williams; Dunning, 1990).

Foi o trabalho que resultou na produção destes livros que levou nossa pesquisa contínua a ser financiada pelo Football Trust, a partir de 1982. Foi em 1987 que o Trust nos financiou sob o nome de Sir Norman Chester Centre for Football Research, um nome que escolhemos para homenagear o falecimento de Sir Norman Chester, que foi o Diretor do Nuffield College Oxford, que foi um dos nossos principais apoiadores e que fez importantes contribuições ao estudo e administração deste esporte.

Foi em 1992 que eu e Murphy, com o auxílio de outro colega, Ivan Waddington, fundamos o Centre for Research into Sport and Society. Quase simultaneamente, John Williams rompeu publicamente conosco, ostensivamente com base na premissa absurda de que confiávamos demais na obra de Elias, e que seus textos eram "muito abstratos", quando, ao contrário, eles são bastante concretos e com grande riqueza de dados. Eu, Murphy e Waddington continuamos até hoje a trabalhar juntos, produzindo livros como Sport, Health and Drugs: a Critical Sociological Perspective (Waddington, 2000), Sport Histories: Figurational Studies of the Development of Modern Sports (Dunning; Malcolm; Waddington, 2004), Sport: Critical Concepts in Sociology (Dunning; Malcolm, 2003) e Fighting Fans: Football Hooliganism as a World Phenomenon (Dunning et al., 2002).

Traduzido do inglês por Édison Gastaldo

Horizontes Antropológicos, Porto Alegre, ano 14, n. 30, p. 223-231, jul./dez. 2008 


\section{Referências}

DUNNING, E.; MALCOLM, D. (Ed.). Sport: critical concepts in sociology. London: Routledge, 2003. 4 v.

DUNNING, E.; MALCOLM, D.; WADDINGTON, I. Sport histories: figurational studies of the development of modern sports. London: Routledge, 2004.

DUNNING, E.; MURPHY, P.; WILLIAMS, J. The roots of football hooliganism: an historical and sociological study. London: Routledge and Kegan Paul, 1988.

DUNNING, E. et al. (Ed.). Fighting fans: football hooliganism as a world phenomenon. Dublin: University College Dublin Press, 2002.

ELIAS, N.; DUNNIG, E. A busca da excitação. Lisboa: Difel, 1995.

MURPHY, P.; WILLIAMS, J.; DUNNING, E. Football on trial: spectator violence and development in the football world. London: Routledge, 1990.

WADDINGTON, I. Sport, health and drugs: a critical sociological perspective. London: Spon, 2000. 